\title{
Sensory Transcendental Therapy
}

\author{
Karen Phillip* \\ Counselling Psychotherapist \& Clinical Hypnotherapist, Australia
}

Submission: September 7, 2017; Published: September 13, 2017

*Corresponding author:: Karen Phillip, Counselling Psychotherapist \& Clinical Hypnotherapist, Australia, Email: karendp@bigpond.net.au

\section{Introduction}

As my research and practice in the field of counseling expands, I see the clear and positive results of current standard therapies. However, I find a gap in the speed of progression that could be improved with a more developed combination of these therapies. I have therefore developed a Sensory Transcendental Therapy (STT), which aims to engage the person out of their comfort zone; get outside and become aware of how all their senses engage; move physically to stimulate the body, mind and processing and be aware of how the counseling discussion enhances or dims certain sensors of the person. While standard methods of counseling show benefits, it takes too long to get major progressive benefits for some patients. Adding all sensors, stimulating mind and body and challenging them with pattern interrupt will create a more complete therapeutic tool. Many counselors are not trained in this practice at all. I have learned much as a clinical hypnotherapist, and so wish to combine some of those parts with counseling-enhanced skills. The therapy combines aspects of standard therapies such as Cognitive Behavioural Therapy, while considering research which tells us outside environments and movement allow us to process faster and with more clarity.

\section{Research and outline}

Sensory Transcendental Therapy (STT) can be described in the following phrase: A psycho-therapeutic counseling session that is held outside the frame of a clinical counseling office. The patient is encouraged to feel more at ease and take in nature (including sight, sounds, feelings, smells of the environment) during a side-by-side walk with a therapist. An outdoor walk takes the person to new and different places, out of their comfort zone, and enables them to more freely discuss their issues.

STT can be likened to Walk and Talk Therapy (WTT), where clients are encouraged to walk side-by-side with the therapist in an outdoor scenario. However, STT takes a more developed and structured approach, incorporating reflective pauses, analysis of body language and Cognitive Behavioural Therapy (CBT) or Solution Focused Therapy, while retaining the benefits of WTT.
WTT has reported positive results for psychologists who have practiced it with difficult or 'closed' patients, many of whom find the enclosed one-on-one of a counseling room too intimidating to 'open up' and understand their issues [1,2].

Movement has long been seen as an excellent supplement to therapy, with research showing vast improvements on the severity of depression diagnoses after periods of prescribed exercise [3]. Building on this theory, simultaneous non-strenuous exercise and counseling has been found to be more effective in treating depressive symptoms than standard counseling [4].

Using the outdoors as a setting for psychotherapy has also been proven to have positive effects on the speed of breakthroughs with patients who find it difficult to 'open up' in a formal counseling scenario. When outside and experiencing nature, patients have reported feeling more calm and aware of their own thoughts, and reported a generally more positive frame of mind [5]. The 'frame' of psychotherapy is a concept that a therapist has to be very aware of when conducting sessions outside the confines of a designated room. The 'frame' describes an image of confidentiality and therapist-client relationships, which must be adhered to in order to keep the safety and integrity of psychotherapy treatment [6]. By taking the 'frame' of a session outside, the counselor must ensure that the patient is comfortable with this, and that the experience should be treated no differently than a standard counseling session. STT replicate all of the benefits described.

\section{Therapy session description}

A one-hour therapy session could consist of a 10-minute walk, with the client being encouraged to employ all their senses by touching the flowers, smelling the air and viewing the environment. If the client feels any thoughts or feelings rising during this time, they are asked to bring these forward. This could be followed by a five-minute pause, to apply CBT where necessary.

A particular topic could be applied to a session, such as a rise in anxiety or an unexplained drop in mood. There would 
be a time to stop, sit and look directly at the person to enhance the therapy used, which would be CBT and solution focused. This approach could then be evaluated, and the patient asked if they want to continue walking for longer or if they feel more comfortable stopping after 10-15 minutes. STT sessions can be designed to suit the patient and their particular needs. If the client expresses a major emotional moment during a session, this is when a pause would be suggested to discuss the pattern of the thoughts. The problem would be tackled using traditional therapeutic remedies, and more positive thought processes would be encouraged.

The inherent problem with traditional therapy is that most depressed or anxious people fail to see their available options during a time of panic; this leads to feeling stuck and lost. An outdoor setting is provided to show the patient a more relaxing view of the world, in the hope that they can see the 'bigger picture'. It should also be noted that some patients may also withhold thoughts and feelings from a therapist - this is part of the process and is often alleviated once rapport is established. The patient's body language should be taken into account. Do they appear nervous? Are they interested in the environment, or withdrawing into themselves? These should be noted and discussed at an appropriate time.

\section{Conclusion}

There is currently little written on walk-talk therapy and nothing on STT, as this is new, but all research does point to the advantages of the being outside and including movement in sessions. While WTT does include this to a degree, it differs from STT in that it does not seem to engage all sensors. I have used STT now for over 2 years and found clients' responses are enhanced and expedited. About 40 people have used STT against non-STT treatments and results were faster for those using STT; all patients involved had similar issues and needs.

\section{References}

1. Doucette PA (2004) Walk and talk: An intervention for behaviorally challenged youths. Adolescence 39(154): 373-388.

2. Hays K (1999) Working it out: Using exercise in psychotherapy. Washington, DC: American Psychological Society.

3. Danielsson L, Noras AM, Waern M, Carlsson J (2013) Exercise in the treatment of major depression: a systematic review grading the quality of evidence. Physiotherapy theory and practice 29(8): 573-585.

4. Jacquart SD, Marsha HH, Dos Santos H, Luu SM, Berk LS, et al. (2013) The effects of simultaneous exercise and psychotherapy on depressive symptoms in inpatient, psychiatric older adults. Advances in mindbody medicine 28(4): 8-17.

5. Revell S, Duncan E, Cooper M (2014) Helpful aspects of outdoor therapy experiences: An online preliminary investigation. Counselling and Psychotherapy Research 14(4): 281-287.

6. Langs RJ (1975) The therapeutic relationship and deviations in technique. International journal of psychoanalytic psychotherapy 4: 106-141.

\section{Your next submission with Juniper Publishers will reach you the below assets}

- Quality Editorial service

- Swift Peer Review

- Reprints availability

- E-prints Service

- Manuscript Podcast for convenient understanding

- Global attainment for your research

- Manuscript accessibility in different formats ( Pdf, E-pub, Full Text, Audio)

- Unceasing customer service

Track the below URL for one-step submission https://juniperpublishers.com/online-submission.php 